\title{
ORGANIZATION OF ECOLOGICAL MONITORING OF CONSTRUCTION
}

\section{Osypova A. A, Savenko V. I.}

\section{INTRODUCTION}

The volume of construction in Ukraine, as a country with developed industry, is characterized as large-scale, which is why the construction industry occupies an important place among the factors of transformation and environmental pollution. However, existing organizational and technological solutions and measures for environmental protection in the process of construction of industrial and civil objects are insufficiently developed and detailored, not integrated into an orderly system, which significantly increases the costs of construction entities for their reconstruction. The issues of operational environmental monitoring and decision-making regarding the localization of identified negative emissions of substances and impacts remain open.

Various aspects of the problematic question raised, concerning the improvement of the basics of environmental protection measures in construction, including the organization of environmental monitoring, are covered in the works of authors and other works of scientists of the world community.

Developed by the author of the classification of factors and major sources of negative impact, as well as a system of typical organizational and technological solutions for the revitalization of construction production processes, ordered by the importance of protected and restored environmental objects, are sufficient only for effective use when designing technology and organizing the construction of facilities. Therefore, the issues of prompt elimination of the effects of environmental pollution during construction remain open.

The scientific substantiation of the organizational and functional structure of environmental monitoring during the construction of structures was chosen for the purpose of this article. The purpose of environmental monitoring is to respond promptly to changes in controlled parameters that describe the current state of the environment where the construction takes place. Therefore, the task of monitoring is, firstly, to receive timely information on the state of the environment and, secondly, to localize the negative impact quickly. 


\section{Substantiation of the proposed organizational and functional structure of environmental monitoring}

The substantiation of the organizational and functional structure of environmental monitoring is carried out by experimental modeling of possible organizational and technological decisions; the subject of modeling were:

A. Organizational structure of the environmental safety point (PEB) with an automated environmental monitoring system (ASEM);

B. Functional structure of environmental monitoring.

Models of organizational and functional structures include: 1 . The purpose of creating a structure; 2. The main purpose (function) of the structure; 3. Organizational or functional scheme; 4. Logistical support.

A. Organizational structure of the environmental safety point (PEB) with an automated environmental monitoring system (ASEM).

1. The goal of creating and operating an environmental safety facility is to protect environmental objects from the adverse effects of construction processes.

An environmental safety facility is created at each site and operates throughout the life of the facility.

2. The main purpose of the environmental safety point is the immediate and rapid removal of hazardous contaminants from the construction site and prompt localization of the negative impact revealed by the environmental monitoring means.

3. Organizational scheme of PEB (Fig. 1).

The personnel of the point of environmental safety is appointed by order of the head of the construction organization, whose staff is formed within the existing staffing of the construction organization.

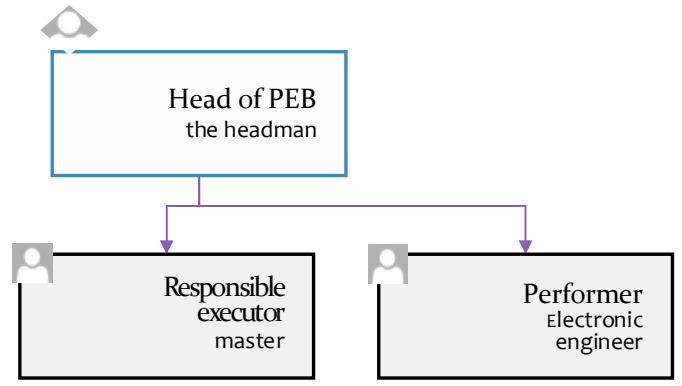

Fig. 1. Organizational chart of the environmental safety point (PEB)

The functions of the PEB chairman are given to the responsible contractor (superintendent, head of the site), the responsible contractor to the master (superintendent), and the executor to the electronic engineer who is involved in permanent work at the construction site. 
Additional revitalization works and activities are performed by construction workers engaged in construction and assembly work and are reimbursed at the expense of general construction costs.

2. Logistics of PEB.

Logistical support is provided on the basis of picking up of PEB with a complex of specially selected inventory, devices and equipment and consisting of:

1. A complete set of equipment for immediate and quick removal of dangerous contaminants; containers with sorbents, containers for the transport of radiation substances, containers with sand for the collection of oil, fuel, chemical additives;

2. Complete set of instruments and laboratory equipment: - gas, dust and noise analyzers, electromagnetic radiation and radiation meters, integrated into an automated information collection and analysis system (ACEM) for ongoing monitoring of the state of degraded environmental elements - extent pollution of atmospheric air, waters of reservoirs, soil and groundwater, levels of noise impact, electromagnetic and radiation radiation, nature and levels of damage to vegetation and fauna.

The structure of these kits by their composition and quantity depends on the volume of possible release of hazardous substances, construction conditions, the nature of its distribution into technological zones and the accepted composition of contractors - the number of simultaneously working units of workers.

B. Functional structure of environmental monitoring regulates the interaction of the information and control system with the sensor system and the object of construction (Fig. 2)

The timely receipt of information about the state of the environment is ensured by the functioning of an automated environmental monitoring system (ASEM), as an information and control system within the hardware and software system in the form of a computer system of the required performance and a system of connected sensors, fixing the magnitude of the controlled parameters (Fig. 2 ): 1) degree of air pollution (gas and dust analyzers); 2) the degree of pollution of the waters of reservoirs, soil and groundwater (analyzers of water, soil, sediments); 3) noise exposure levels (noise analyzers); 4) levels of electromagnetic and radiation radiation (meters of electromagnetic radiation and radiation).

To automate the processes of gathering current information and its statistical processing, a developed application subroutine implemented in MS Excel, PPMDovkilliaOsypovaAnastasia (see Fig. 3) is used.

An example of the statistical processing of current information on the maximum daily sound pressure levels measured directly at a construction site is shown in Fig. 4. 


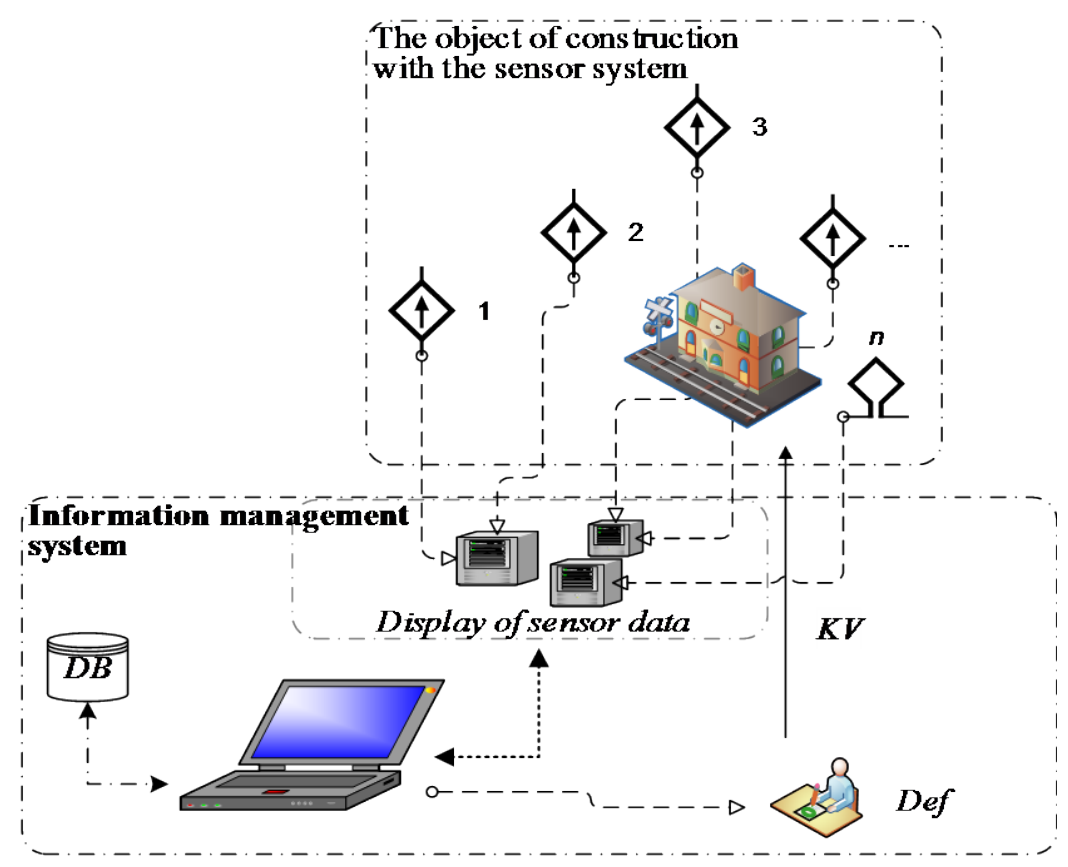

Fig. 2. Interaction of the information-control system with the sensor system and the object of construction: $1,2,3, \ldots, n$ - sensors

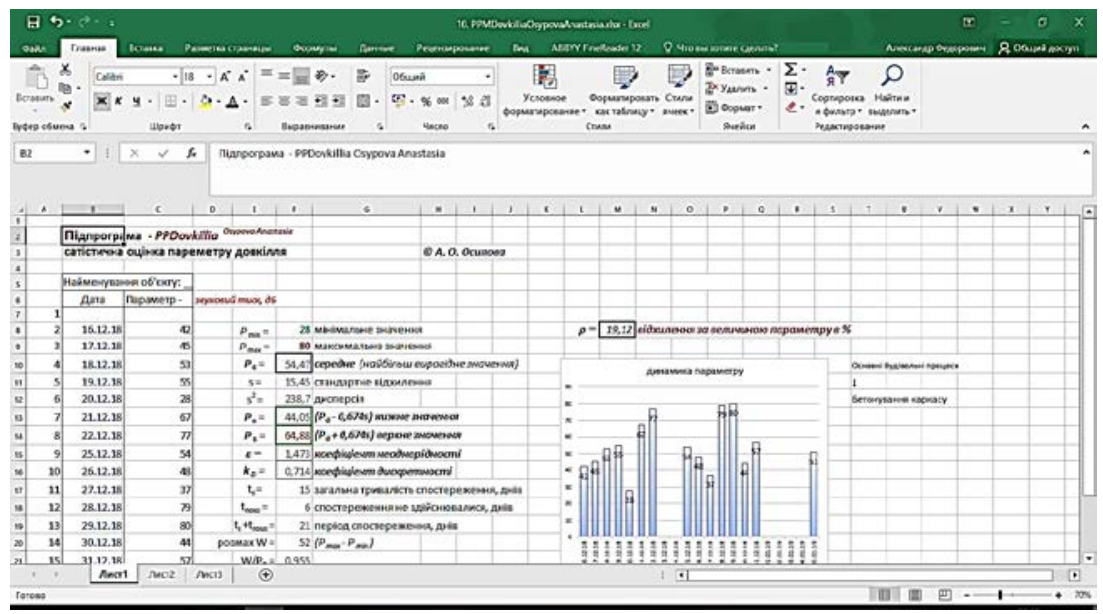

Fig. 3. Graphical shell of PPDovkilliaOsypovaAnastasia subroutine statistical estimation of environmental parameter 


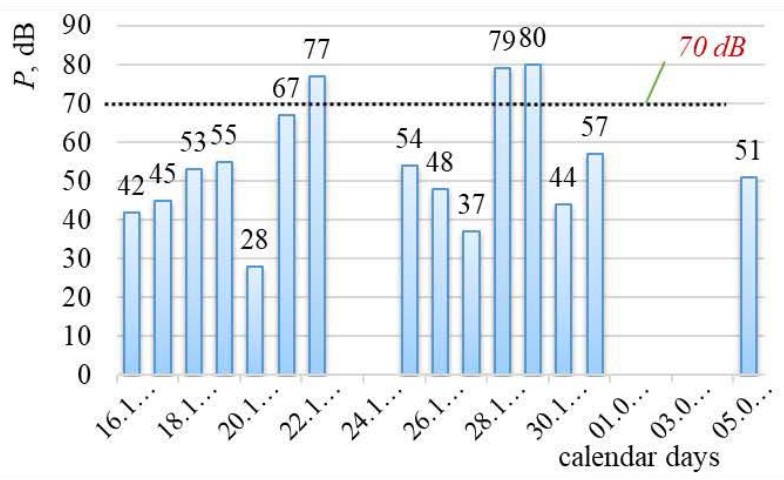

Fig. 4. Dynamics of sound pressure $(P, d B)$ at the construction site (noise source)

The analysis shows that on 21 and 27 and 28 December this year, sound pressures exceeded the maximum permissible for residential development (up to $70 \mathrm{~dB}$ ).

Operational localization of the negative impact is carried out by performing additional revitalization work and measures, including the use of an existing set of equipment for immediate and rapid removal of dangerous contaminants.

Additional revitalization works and measures, in the form of managerial influence (CV, see Fig. 2), are formed by ODA on the basis of:

- information received on the current state of the environment, the presence and levels of exceedances of MPC by environment (air, water, soil, etc.) and by the levels of negative impacts (noise, light, etc.);

- volumes of revitalization works and measures actually completed in the preparatory period;

- Databases (DBs) about typical OTP-complexes [14] and data on earlier performed revitalization measures at other objects of the construction organization.

For example, an analysis of the dynamics of sound pressures at a construction site (see Figure 4) and the sources of their origin (be it the work of hand-held perforators) need to equip jobs with sound-absorbing screens.

The structure and quantitative composition of the sensor system and their location on a particular construction takes into account:

1) there are negative emissions and impacts generated during the execution of the processes of selective-extreme structure;

2) physical and geographical location, microclimatic, geological and hydrological characteristics of the construction site; are determined according to the relevant sections of the EIA developed within the work project; 
Typical structure of sensors-devices is recommended of environmental safety

\begin{tabular}{|l|}
\hline \multicolumn{1}{|c|}{ Appliance name and scope } \\
\hline $\begin{array}{l}\text { Gas analyzer testo 535, } \\
\text { industrial gas analyzer testo } 350 \\
\text { Price*: 267,60 - } 10 \text { 278,55 USD. } \\
\text { Control of air pollution by the exhaust gases }\end{array}$ \\
$\begin{array}{l}\text { 1. Walcom HT-9600 dust dust analyzer } \\
\text { Price *: 208,04 USD } \\
\text { Assessment of air quality by determining the reducing } \\
\text { microdispersed dust particles and inhalation dust particles in the air, } \\
\text { as well as for measuring temperature and relative humidity }\end{array}$ \\
\hline
\end{tabular}

1. Sound recorder with PC connection Tenmars TM-103 Price *: 7000,00 UAH

Control of noise pollution in the general frequency range $30 \ldots 130 \mathrm{~dB}$

1. EZODO EM-191 industrial frequency magnetic field intensity analyzer

Price *: $2230.00 \mathrm{UAH}$

Measurement of magnetic induction in the low frequency range (EMF) from 30 to $300 \mathrm{~Hz}$.

1. MKS-05 "TERRA" dosimeter radiometer

Price *: 7896,00 UAH

Dosimetric and radiometric monitoring at the construction site

1. TSS PORTABLE analyzer

Price *: 7530,00 UAH

Surface water, soil and groundwater monitoring in ditches, vegetation and sediment analysis

* - the price is given at the beginning of April 2019 (the total cost of a set of devices - 36,2... 37,0 thousand $U A H$ ) 


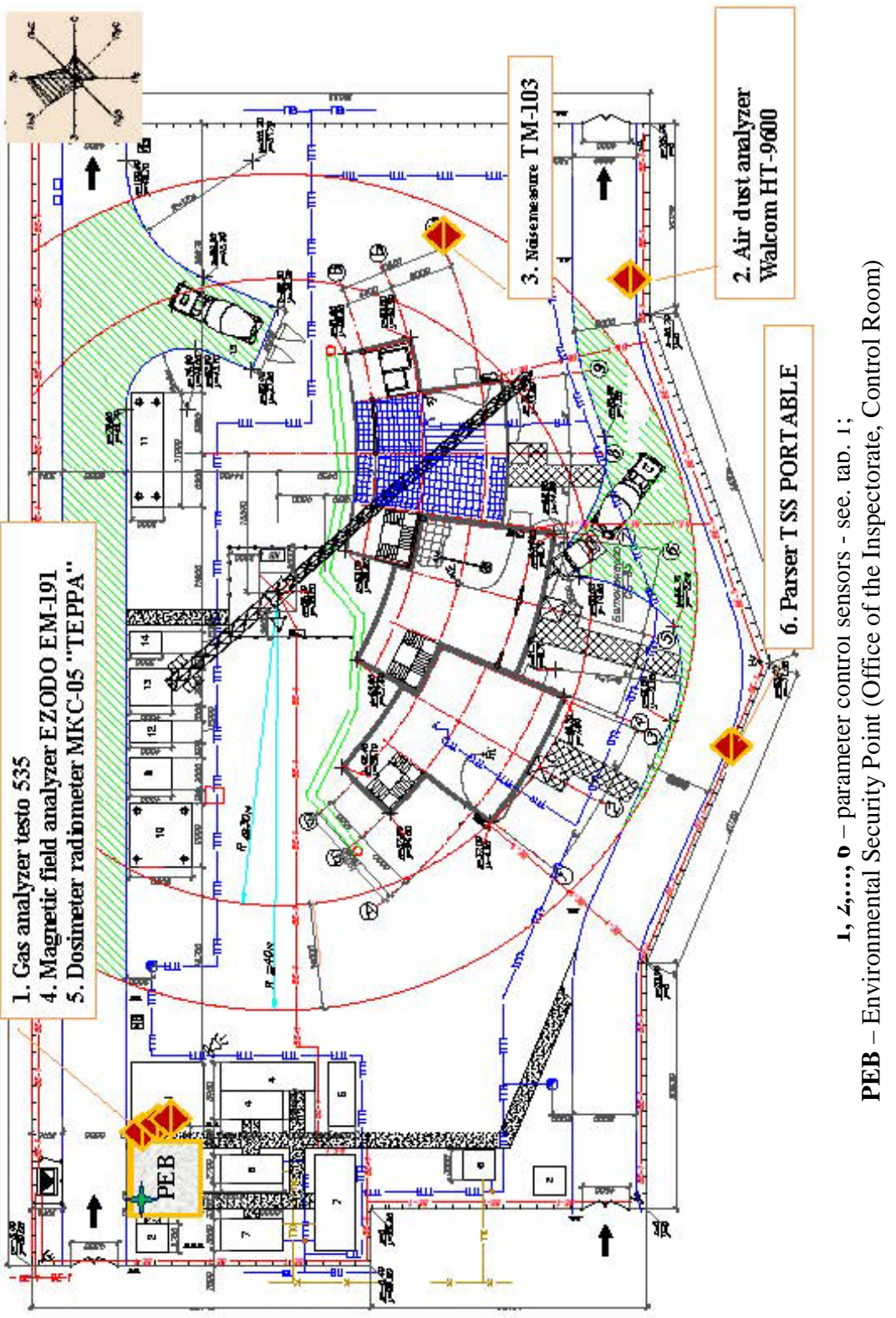


3) urban planning features: the type of anthropogenic landscape that is being transformed (quiet or noisy street, park area, etc.);

4) proximity to nature, residential and industrial areas, architectural and historical monuments and more.

An example of the location of the environmental monitoring system is shown in Fig. 5, and their recommended typical structure - in Table. 1.

The location of the sensors takes into account the wind direction (sensor \# 2 - Walcom HT-9600 air dust analyzer) and the available natural terrain - sensor No. 6, which controls surface and groundwater located in the monitoring well at the foot of the slope, and the sound level meter TM 103 .

\section{CONCLUSION}

Established and developed organizational and functional structures are applied bases of organization of ecological monitoring of construction aimed at eliminating the causes of negative impact of construction production processes on the environment.

\section{SUMMARY}

The scientific substantiation of the organizational and functional structure of environmental monitoring during the construction of industrial and civil structures has been performed. Models of organizational and functional structures include the purpose of creation and the main purpose (function) of the structure, organizational or functional schemes, as well as logistics.

\section{REFERENCES}

1. Dzhigirey VS Ecology and environmental protection: textbook. manual / VS Dzhigirey. - 5th edition, vypr. and ext. - K.: Knowledge, 2007. $-422 \mathrm{p}$.

2. Stolberg FV City Ecology: A Textbook for Students. high schools / Under the total. ed. F. W. Stolberg. - K.: Libra, 2000. - 463 p.

3. Sugrobov NP Building ecology: Textbook. Benefit / NP Sugrobov. M.: Academy, 2004. -413 p.

4. Tetior AN Architectural and Construction Ecology: Textbook. manual / AN Tetior. - M.: Academy, 2008. - 361 p.

5. The effect of ecological resonance at the concentration of construction (real estate) / Telichenko V.I. and other // Industrial and civil engineering. - 2010. - № 6. - pp. $14-16$.

6. Osypova A.A. Methods of research and systematization of factors of construction production that negatively affect the state of the environment / A.A. Osypova // Modern problems of architecture and town planning: Scientific and Technical Collection. No. 50 // Kiev, KNUBA - 2018. P. 278-282. 
7. Osypova A.A. Structural analysis of ecologically dangerous factors of construction production. Sources of pollution / A.A. Osypova // Urban planning and territorial planning: Scientific and Technical Collection. No. 67 // Kiev, KNUBA - 2018. - P. 356-365.

8. Osipova AA Research and substantiation of an orderly system of organizational and technological solutions for the revitalization of construction production processes // Ways of improving the efficiency of construction in the conditions of formation of market relations: collection. of Sciences. - K.: KNUBA, - 2019. - № 39. - Pp. 57-70.

\section{Information about the authors:}

Osypova A. A.,

Post-graduate Student of the Department of Organization and Management of Construction, Kyiv National University of Construction and Architecture 31, Povitroflotsky Ave., Kiev, 03680, Ukraine

Savenko V. I.,

Candidate of Technical Sciences, Doctor of Technical Sciences(RF), Professor at the Department of Organization and Management of Construction, Kyiv National University of Construction and Architecture 31, Povitroflotsky Ave., Kiev, 03680, Ukraine 